\title{
Sistem Pengendalian dan Monitoring Distribusi Air Berbasis Nodemcu 8266
}

\author{
Laxsmy Devy $^{1 *}$, Yul Antonisfia ${ }^{2}$, Monica Febrina $^{3}$ Suryadi $^{4}$ \\ 1234 Jurusan Teknik Elektro Politeknik Negeri Padang \\ Jurusan Teknik Elektro Politeknik Negeri Padang, Jl. Limau Manih Padang, 25164, Indonesia \\ *Corresponding Author, email : laxmy_d@yahoo.co.id
}

\begin{abstract}
Abstrak-Pengelolaan air bersih di kelola oleh Perusahaan Daerah Air Minum (PDAM) yang berpusat pada masingmasing pemerintah daerah. Pendistribusian air ke konsumen tidak dapat dilakukan merata karena sistem pendistribusian air dan pemantauan secara manual. Mengatasi permasalahan tersebut, Sistem Pemerataan Distribusi Air ke Konsumen dapat digunakan untuk monitoring dan mengontrol distribusi air. Sistem ini mengatur debit dan zona waktu pendistribusian air ke konsumen. Debit air dideteksi oleh sensor waterflow, valve dihubungkan dengan motor servo dan zona waktu menggunakan RTC DS1307. Pompa air dikendalikan untuk menjaga volume air pada bak penampungan. Level air pada bak penampungan dideteksi menggunakan sensor ultrasonik HC-SR04. Pendistribusian air dimonitoring pada PC(Personal Computers) dan smartphone menggunakan pemrogramman Delphi dan Thingspeak. Pembacaan debit air yang dihasilkan pada saat waktu penggunaan puncak untuk masing-masing kran yaitu 1.9 : 1.8 : 1.8 sedangkan pada waktu penggunaan biasa perbandingan pendistribusian awal terhadap masing-masing kran yaitu $2.5: 2.3,1: 1$ dan $2.5: 2.3$.
\end{abstract}

Kata kunci : Mikrokontroler, RTC DS1307, waterflow, ultrasonic HC-SR04, servo, Delphi, Thingspeak

\begin{abstract}
Clean water management is managed by a Perusahaan Daerah Air Minum (PDAM), which is centered on each local government. The distribution of water to consumers cannot be done evenly because of the water distribution system and manual monitoring. Overcoming these problems, the Water Distribution Equity System to Consumers can be used to monitor and control water distribution. This system regulates the debit and time zone for water distribution to consumers. Water discharge is detected by the water flow sensor, and the valve is connected to the servo and time zone using RTC DS1307. The water pump is controlled to maintain the volume of water in the reservoir. The water level in the reservoir is detected using the HC-SR04 ultrasonic sensor. Water distribution is monitored on PCs (Personal Computers) and smartphones using Delphi programming and Thingspeak. The reading of water discharge is generated during peak use times for each faucet is 1.9: 1.8: 1.8 while at the time of normal use the ratio of the initial distribution to each faucet is 2.5: 2.3, 1: 1 , and 2.5: 2.3.
\end{abstract}

Keywords: Microcontroller, RTC DS1307, waterflow, ultrasonic HC-SR04, servo, Delphi, Thingspeak

(C) 2020 Elektron Jurnal Ilmiah

\section{PENDAHULUAN}

Indonesia merupakan daerah tropis dengan dua musim, kemarau dan musim hujan. Saat musim hujan ketersedian air sangatlah berlimpah, namun saat musim kemarau ketersedian air kurang malahan sampai kekeringan. Secara geografis Indonesia merupakan daerah pegunungan dengan dataran yang tidak rata. Aliran air mengalir dari daerah yang lebih tinggi menuju daerah yang lebih rendah. Sumber air tawar alami diperoleh oleh masyarakat antara lain dari sungai, mataair dan air hujan. Untuk mememenuhi kebutuhan sehari-hari ketersediaan air untuk masyarakat perlu pengelolaan. PDAM (Perusahaan Daerah Air Minum) salahsatu pengelola air untuk masyarakat seperti yang diperlihatkan pada gambar 1 .

Permasahan yang timbul dalam pengelolaan air biasanya saat musim kemarau. Distribusi air ke masyarakat tidak dapat dilayani dengan maksimal. Biasanya air didistribusikan bergiliran, dimana konsumen ada yang mendapatkan air ada yang tidak.

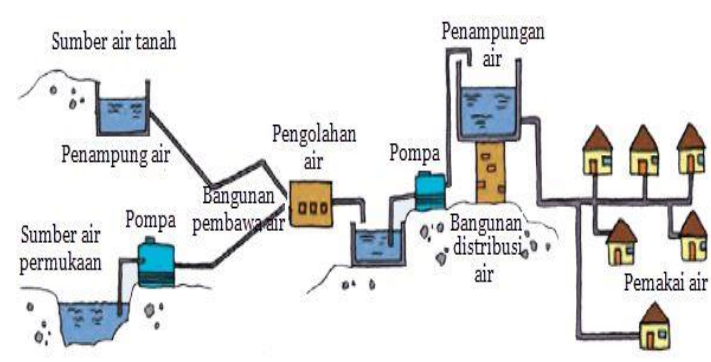

Gambar 1. Daur pengelolaan air

Sumber : https://www.mikirbae.com/2015/04/pemanfaatansumber-daya-air.html

Begitu juga yang terjadi pada konsumen yang berada di daerah ketinggian seringkali tidak mendapatkan air sampai berhari-hari. Dari permasalahan tersebut maka diperlukan sistem yang dapat memperbaiki pengeloaan air agar lebih baik. 'Sistem Pemerataan Distribusi Air ke Konsumen' ini akan mengatur pemerataan debit air dan pendistribusian bergilir ke konsumen terutama pada saat musim kemarau, baik konsumen yang berada di dataran tinggi maupun di dataran rendah. 
Penelitian yang terkait sebelumnya antara lain I D.M.B.A.Darmawan dkk, dengan judul Sistem Instalasi Air Rumah Terkomputerisasi Berbasis Mikrokontroler Dengan Perintah Sms[1], Sutono[2], Monitoring Distribusi Air Bersih dan [3], semua penelitian tersebut hanya focus pada monitoring distribusi air tidak pada system pengendaliannya.

'Sistem Pemerataan Distribusi Air ke Konsumen' menggunakan 4 buah sensor water flow yaitu tiga buah sensor water flow pada setiap daerah masyarakat (mewakili dataran tinggi, datar dan rendah) dan satu buah digunakan pada sumber utama. Sensor ultasonik HC-SR04 digunakan untuk pengontrolan kapasitas sumber air yang tersedia pada bak penampungan. Sistem ini menggunakan Motor Servo untuk mengatur pendistribusian air bersih berdasarkan waktu penggunaan. Sistem monitoring sebagai media informasi menggunakan IoT (Internet of Thing) yang berupa node mcu untuk monitoring jarak jauh dan software Delphi untuk monitoring jarak dekat.

\section{METODE}

Metode Penelitian yang dilakukan adalah meliputi perancangan diagram blok, perancangan hardware, perancangan software. Diagram blok sebagai perancangan awal untuk menentukan hardware yang akan digunakan pada 'Sistem Pemerataan Distribusi Air ke Konsumen' . Perancangan hardware meliputi rangkaian-rangkaian sensor, modul mikrokontroller, motor dan driver serta modul monitoring sebagai indikator. Perancangan software sebagai pemroses data yang melaksanakan instruksi-instruksi agar semua sistem dapat bekerja seperti yang diinginkan.

\subsection{Blok Diagram}

Perancangan alat dimulai dengan membuat blok diagram sistem kerja dari keseluruhan rangkaian, pada gambar 2 .

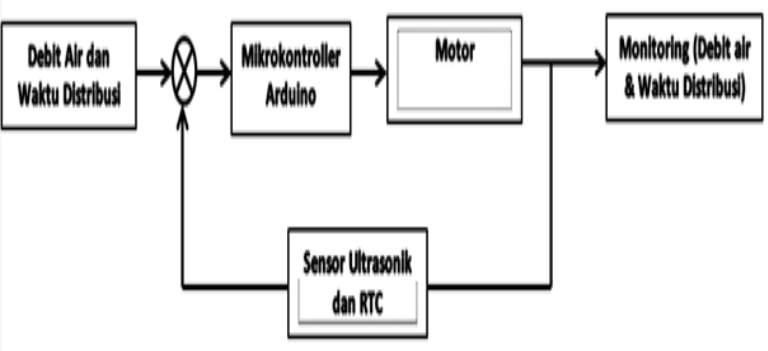

Gambar 2. Blok Diagram sistem hardware keseluruhan

Sistem ini dirancang dengan memanfaatkan mikrokontroller Arduino Mega 2560 Sistem ini akan membaca waktu penggunaan air bersih yaitu dengan menggunakan RTC DS1307. Pembacaan waktu penggunaan air bersih dibagi menjadi dua yaitu pada waktu penggunaan puncak (pagi dan sore) dan waktu penggunaan biasa (siang dan malam). Pada saat waktu penggunaan puncak maka air akan megalir secara bersamaan ke ketiga bagian daerah masyarakat dengan mengatur posisi motor servo pada masingmasing bagian daerah. Debit air yang mengalir pada masing-masing daerah akan dibaca oleh sensor water flow. Pembacaan debit air pada masing-masing daerah dan sumber utama dapat dimonitoring dengan jarak dekat maupun jarak jauh dengan memanfaatkan teknologi IoT (Internet of Thing) menggunakan node mси ESP8266.

\subsection{Perancangan dan Pembuatan Hardware}

\section{A. Rangkaian RTC DS1307}

RTC DS1307 pada gambar 3 digunakan sebagai pembacaan waktu untuk mendistribusikan air bersih PDAM. RTC DS1307 adalah modul dengan 4 pin. Pin $+5 \mathrm{~V}$ terhubung dengan $\mathrm{V}_{\mathrm{CC}}$. Pin GND terhubung dengan Ground, pin SDA terhubung dengan pin 20, SCL terhubung dengan pin 21.

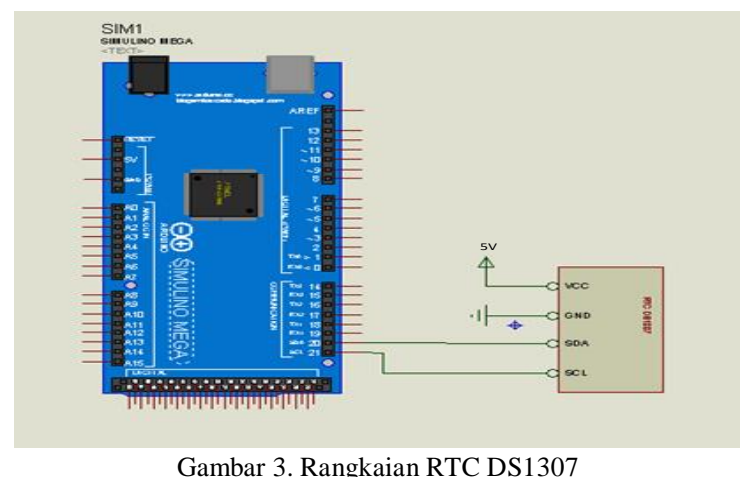

Tabel 1. Pin Arduino Mega2560 dengan RTC DS1307

\begin{tabular}{cc}
\hline Pin Arduino Mega 2560 & RTC DS1307 \\
\hline 20 & SDA \\
\hline 21 & SCL \\
\hline $\mathrm{V}_{\mathrm{CC}}$ & Sumber 5 V \\
\hline GND & Sumber Ground \\
\hline
\end{tabular}

\section{B. Sensor Ultrasonik HC-SR04}

Sensor Ultrasonik HC-SR04 digunakan sebagai pendeteksi ketinggian air berupa kapasitas air dalam bak penampungan air yang terlihat pada gambar 4 . Sensor Ultrasonik HC-SR04 adalah modul dengan 4 pin. Pin $+5 \mathrm{~V}$ terhubung dengan $\mathrm{V}_{\mathrm{CC}}$. Pin GND terhubung dengan Ground, pin trig terhubung dengan pin 5, Echo terhubung dengan pin 6. 


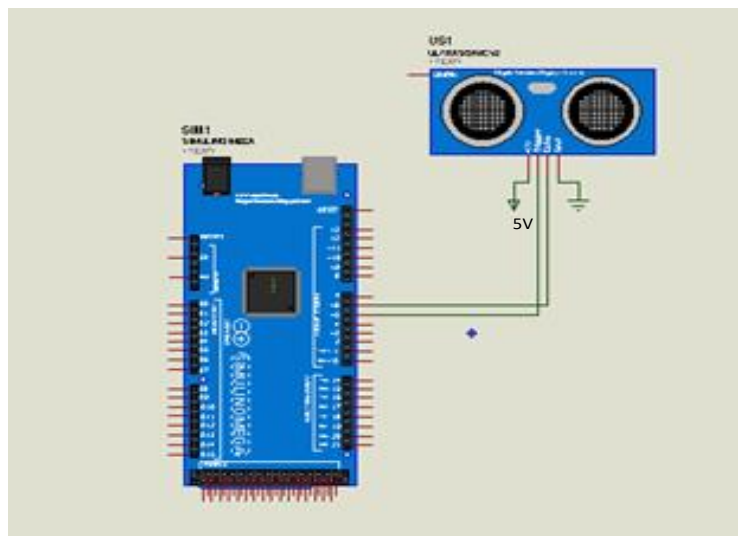

Gambar 4. Rangkaian sensor ultrasonic HC-SR04

Tabel 2. Pin Arduino Mega 2560 dengan sensor ultrasonic HCSR04

\begin{tabular}{ccc}
\hline Pin Arduino Mega 2560 & HC-SR04 (1) & Keterangan \\
\hline 5 & Trigger & Output \\
\hline 6 & Echo & Input \\
\hline VCC & & Sumber 5 V \\
\hline GND & & Sumber Ground \\
\hline
\end{tabular}

\section{Sensor Water Flow}

Rangkaian sensor water flow digunakan sebagai pembacaan debit air yang didistribusikan ke masingmasing daerah masyarakat dan pembacaan debit air yang keluar dari sumber utama. Sensor water flow yang digunakan pada sistem ini ada 4 buah yaitu 3 buah pada setiap daerah konsumen dan 1 buah pada sumber utama. Sensor water flow adalah sensor dengan 3 pin. Pin $+5 \mathrm{~V}$ terhubung dengan $\mathrm{V}_{\mathrm{CC}}$. Pin GND terhubung dengan Ground, pin data masingmasing sensor water flow terhubung dengan pin $19,18,2,3$. Sensor water flow bekerja dengan data interrupt dari arduino agar dapat membaca data debit air yang mengalir.

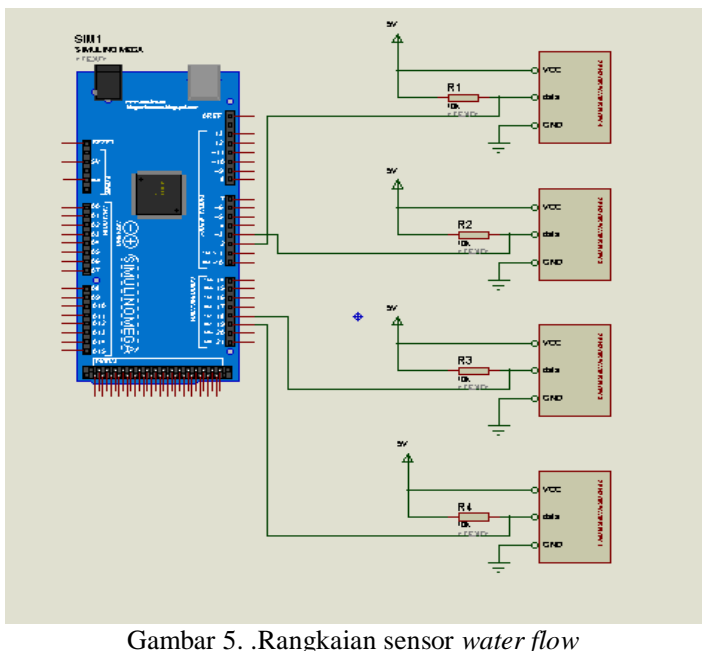

Tabel 3. Pin Arduino Mega2560 dan sensor Water flow

\begin{tabular}{ccc} 
& $\begin{array}{c}\text { Tabel 3. } \\
\text { dan sensor Water flow }\end{array}$ \\
\cline { 1 - 2 } $\begin{array}{c}\text { Pin } \\
\text { Arduino } \\
\text { Mega 2560 }\end{array}$ & Komponen & Keterangan \\
\cline { 1 - 2 } 19 & Data Sensor water flow 1 & Sumberutama \\
\hline 18 & Data Sensor water flow 2 & $\begin{array}{c}\text { Masing-masing } \\
\text { daerah } \\
\text { masyarakat }\end{array}$ \\
\hline 2 & Data Sensor water flow 3 & Sumber 5 V \\
\hline 3 & Data Sensor water flow 4 & Sumber Ground \\
\hline $\mathrm{V}_{\mathrm{CC}}$ & &
\end{tabular}

D. Rangkaian Motor Servo

Rangkaian Servo digunakan sebagai valve pada ketiga daerah konsumen, servo tersebut akan membentuk sudut putarnya berdasarkan inputan sensor water flow. rangkaian output servo memiliki 3 pin yaitu pin $+5 \mathrm{~V}$ terhubung ke pin $\mathrm{V}_{\mathrm{CC}}$ arduino, pin GND terhubung ke ground dan masing-masing data servo terhubung ke pin 10, 11 dan 12 .

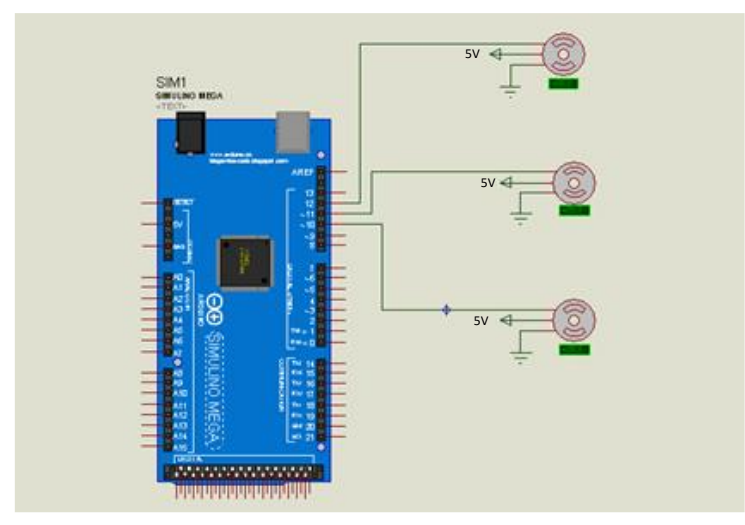

Gambar 6. Rangkaian Servo

Tabel 4. Pin Arduino Mega2560 dan motor servo

\begin{tabular}{cc}
\hline Pin Arduino Mega 2560 & Komponen \\
\hline 10 & Data Servo 1 \\
\hline 11 & Data Servo 2 \\
\hline 12 & Data Servo 3 \\
\hline $\mathrm{V}_{\mathrm{CC}}$ & Sumber 5 V \\
\hline GND & Sumber Ground \\
\hline
\end{tabular}

\section{E. Rangkaian node MCUESP 8266}

Node MCU ESP 8266 digunakan untuk mengirimkan data dari sistem ke monitoring. Modul ESP 8266 bekerja dengan menggunakan koneksi internet agar data yang akan dimonitoring dapat terbaca oleh sistem. Modul nodeMCU ESP 8266 memiliki 4 pin yaitu pin $\mathrm{V}_{\mathrm{CC}}$ terhubung ke $\mathrm{V}_{\text {in }}$ arduino, pin GND terhubung ke Ground arduino, RX dan TX terhubung ke TX dan RX arduino. 


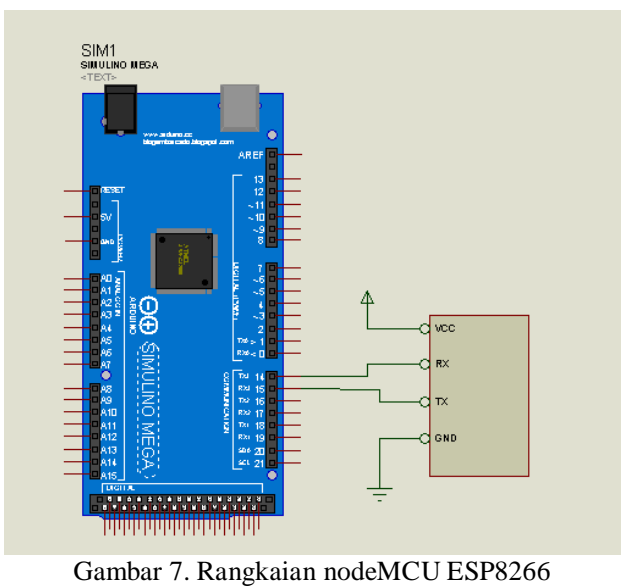

Tabel 5. Pin Arduino Mega2560 dan nodeMCU ESP8266

\begin{tabular}{cc}
\hline Pin Arduino Mega 2560 & nodeMCU ESP8266 \\
\hline 14 & RX \\
\hline 15 & TX \\
\hline Sumber $\mathrm{V}_{\text {in }}$ & Vcc \\
\hline GND & Sumber Ground \\
\hline
\end{tabular}

\section{F. Rangkaian Driver Motor}

Rangkaian ini digunakan untuk mengaktifkan pompa pada sumber dan pompa pada pendistribusian air ke konsumen. Rangkaian driver motor memiliki 3 pin yaitu pin $\mathrm{V}_{\mathrm{CC}}$ terhubung ke $+5 \mathrm{~V}$ arduino, pin GND terhubung ke Ground arduino, IN terhubung ke pin 7 arduino, output pada rangkaian driver menghubungkan pompa dengan tegangan 220 VAC.

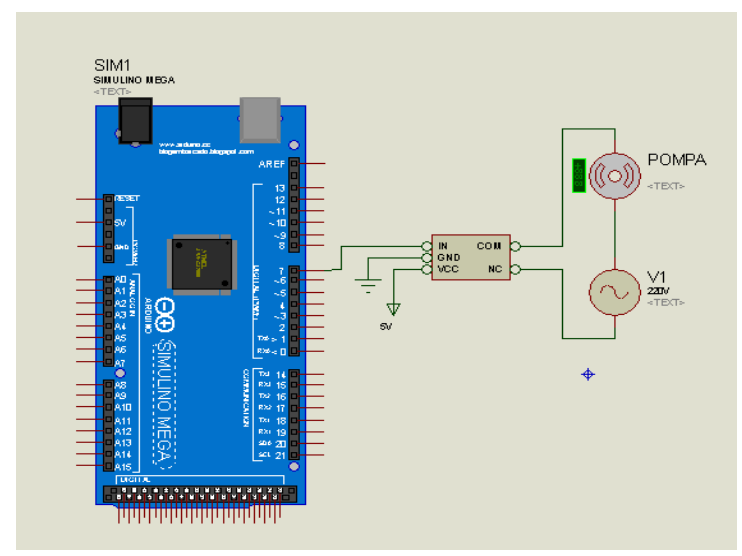

Gambar 8. Rangkaian driver motor

Tabel 6. Pin Arduino Mega2560 dan rangkaian driver motor

\begin{tabular}{cc}
\hline Pin Arduino Mega 2560 & Driver motor \\
\hline 7 & IN1 \\
\hline $\mathrm{V}_{\mathrm{CC}}$ & Sumber 5 V \\
\hline GND & Sumber Ground
\end{tabular}

G. Rangkaian Sistem Pemerataan Distribusi Air ke Konsumen

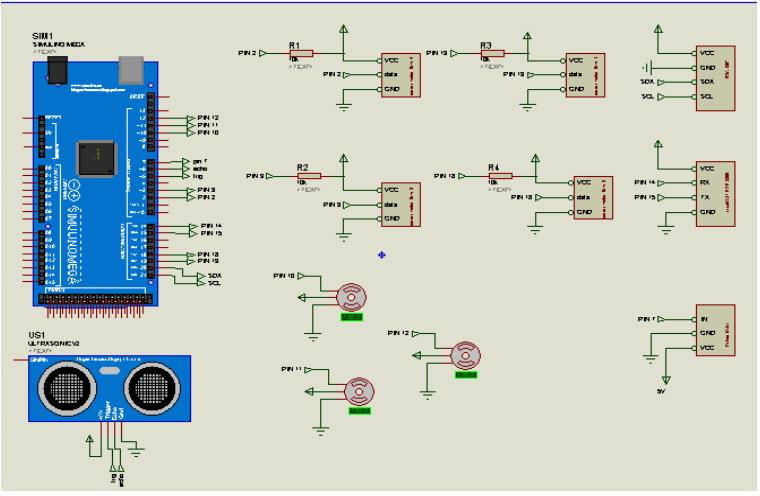

Gambar 9. Rangkaian Sistem Pemerataan Distribusi Air ke Konsumen

Tabel 7. Pin mikrokontroler yang digunakan untuk sensor dan output data.

\begin{tabular}{ll}
$\begin{array}{c}\text { Pin Arduino } \\
\text { Mega ADK } \\
\text { 2560 }\end{array}$ & \multicolumn{1}{c}{ Fungsi } \\
\hline PIN 2 & INPUT sensor water flow 1 (server) \\
\hline PIN 3 & INPUT sensor water flow 2 (daerah tinggi) \\
\hline PIN 19 & INPUT sensor water flow 3 (daerah datar) \\
\hline PIN 18 & INPUT sensor water flow 4 (daerah rendah) \\
\hline PIN 12 & OUTPUT Servo 1 (daerah tinggi) \\
\hline PIN 11 & OUTPUT Servo 2 (daerah datar) \\
\hline PIN 10 & OUTPUT Servo 3 (daerah rendah) \\
\hline PIN 14 & RX nodemcuESP 8266 \\
\hline PIN 15 & TX nodemcuESP 8266 \\
\hline PIN 5 & Trigger ultrasonik \\
\hline PIN 6 & Echo ultrasonik \\
\hline PIN 20 & SDA DS1307 \\
\hline PIN 21 & SCL DS1307 \\
\hline PIN 7 & Driver Motor \\
\hline
\end{tabular}

\subsection{Perancangan Software}

Perancangan software pada alat ini merupakan perancangan untuk pembuatan program dalam arduino mega 2560. Pembacaan nilai RTC digunakan sebagai inisialisasi waktu penggunaan untuk mengaktif kan proses pendistribusian air yaitu pada saat waktu penggunaan puncak yaitu pagi (04.00 sampai 08.59) dan sore (15.00 sampai 18.59) menunjukkan bahwa setiap masing-masing daerah menerima pendistribusian air secara bersamaan yaitu dengan pengaturan valve berupa motor servo yaitu pada daerah tinggi 25 derajat, daerah datar 50 derajat dan daerah rendah 35 derajat. Sedangkan waktu penggunaan biasa yaitu siang (09.00 sampai 14.59) dan malam (19.00 sampai 03.59) menunjukkan bahwa pendistribusian air dilakukan secara bergantian pada setiap masing-masing daerah dengan mengatur pembukaan katub valve oleh motor servo, yakni jika pada daerah tinggi motor servo membuka 40 derajat dan servo daerah yang lain tertutup, jika pada daerah datar motor servo membuka 45 derajat dan servo daerah yang lain tertutup dan jika pada daerah rendah motor servo membuka 30 derajat dan servo daerah yang lain tertutup. 
Kapasitas air pada bak penampungan di deteksi oleh sensor ultrasonik HC-SR04 yang menunjukkan ketinggian tertentu untuk mengaktifkan pompa air yaitu pada jarak ketinggi besar dari $15 \mathrm{~cm}$ menunjukkan bahwa pompa akan aktif dengan mengaktifkan motor driver dan sebaliknya jika kecil dari $15 \mathrm{~cm}$ maka driver motor akan mati untuk mematikan pompa air.

Pembacaan debit air yang dilakukan oleh sensor water flow yang mengalir ke masyarakat dapat di monitoring pada PC dan smartphone dengan memanfaatkan menggunakan komunikasi internet nodeMCU ESP8266 dan juga komunikasi serial Delphi.

\section{HASIL DAN PEMBAHASAN}

Pengujian dilakukan untuk mengetahui apakah sistem yang dibuat telah sesuai dengan yang direncanakan, hal itu dapat dilihat dari hasil yang diperoleh dalam pengujian sistem.Selain itu pengujian juga digunakan untuk mengetahui tingkat kinerja dari alat tersebut.

\section{A. Rangkaian RTC DS1307}

Pengujian RTC dilakukan dengan cara mengatur waktu pada RTC berdasarkan program Set-Time yang di upload pada arduino dengan konfigurasi pin SDA dan SCL serta $\mathrm{V}_{\mathrm{CC}}$ dan Ground pada RTC telah terhubung ke arduino. Adapun program untuk mengatur waktu RTC yaitu:

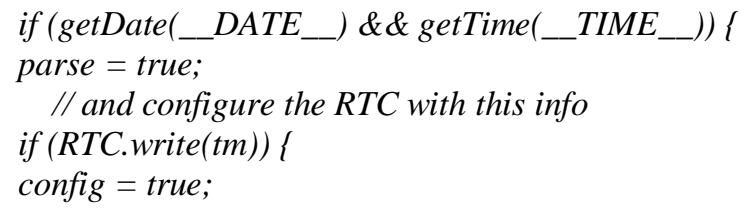

Tabel 8. Hasil pengujian data waktu rangkaian RTC DS 1307

\begin{tabular}{cc}
\hline waktu pada PC(laptop) & waktu pada RTC \\
\hline 9.23 & 9.22 .26 \\
\hline 9.28 & 9.27 .26 \\
\hline 9.33 & 9.32 .26 \\
\hline 9.36 & 9.35 .26 \\
\hline
\end{tabular}

Jk, Time $=09: 32: 26$, Date $(\mathrm{D} / \mathrm{M} / \mathrm{Y})=10 / 9 / 2018$

Pengujian dilakukan dengan mengukur tegangan pada $\mathrm{V}_{\mathrm{CC}}$, SDA dan SCL pada RTC terhadap Ground. Pengukuran dilakukan pada tiga titik pengukuran (TP) pada gambar 10

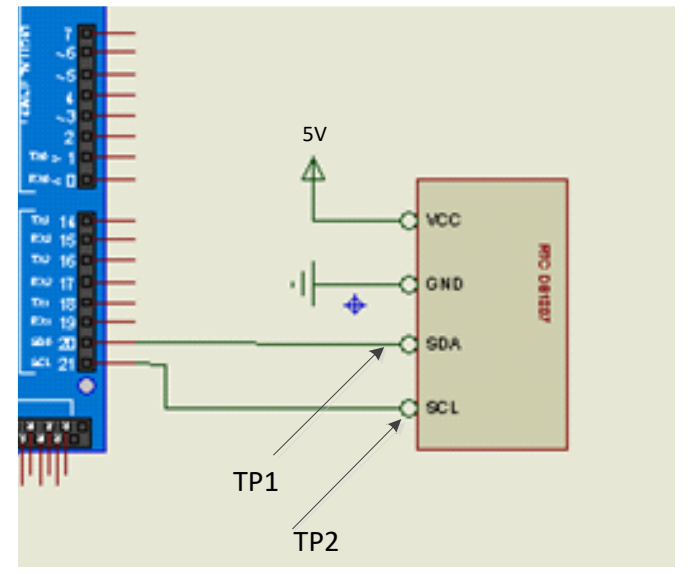

Gambar 10. Rangkaian RTC DS 1307

Tabel 9. Hasil uji pada titik pengukuran rangkaian RTC DS 1307

\begin{tabular}{cc}
\hline Titik Pengukuran & Vout(V) \\
\hline TP1 Vcc & 4.98 \\
\hline TP2 SDA (PIN 20) & 4.96 \\
\hline TP3 SCL(PIN 21) & 4.95 \\
\hline
\end{tabular}

Pengujian data RTC pada tabel 9 menunjukkan bahwa waktu yang di tampilkan pada RTC lebih lambat 34 detik dibandingkan dengan pembacaan waktu pada PC laptop. Jika sistem telah dimatikan pengaturan waktu pada RTC akan tetap aktif dan masih bisa membaca waktu karena RTC memiliki sumber tegangan sekunder yang berasal dari battery $3 \mathrm{~V}$ yang terpasang pada body RTC, sehingga tidak perlu lagi untuk melakukan pengaturan ulang untuk waktu RTC.

Berikut adalah tabel logika RTC untuk mengaktifkan valve pada masing-masing kran.

Tabel 10. Tabel logika pengaktifan valve berdasarkan waktu

\begin{tabular}{cccc}
\hline & \multicolumn{3}{c}{ pengaktifan valve } \\
\cline { 2 - 4 } waktu (WIB) & $\mathrm{kran} 1$ & $\mathrm{kran} 2$ & $\mathrm{kran} 3$ \\
\hline $04.0-08.59$ & $\sqrt{ }$ & $\sqrt{ }$ & $\sqrt{ }$ \\
\hline $09.00-09.59$ & $\sqrt{ }$ & $\mathrm{X}$ & $\mathrm{X}$ \\
\hline $10.00-10.59$ & $\mathrm{X}$ & $\sqrt{ }$ & $\mathrm{X}$ \\
\hline $11.00-11.59$ & $\mathrm{X}$ & $\mathrm{X}$ & $\sqrt{ }$ \\
\hline $12.00-12.59$ & $\sqrt{ }$ & $\mathrm{X}$ & $\mathrm{X}$ \\
\hline $13.00-13.59$ & $\mathrm{X}$ & $\sqrt{ }$ & $\mathrm{X}$ \\
\hline $14.00-14.59$ & $\mathrm{X}$ & $\mathrm{X}$ & $\sqrt{ }$ \\
\hline $15.00-18.59$ & $\sqrt{ }$ & $\sqrt{ }$ & $\sqrt{ }$ \\
\hline $19.00-19.59$ & $\sqrt{ }$ & $\mathrm{X}$ & $\mathrm{X}$ \\
\hline $20.00-20.59$ & $\mathrm{X}$ & $\sqrt{ }$ & $\mathrm{X}$ \\
\hline $21.00-21.59$ & $\mathrm{X}$ & $\mathrm{X}$ & $\sqrt{ }$ \\
\hline $22.00-22.59$ & $\sqrt{ }$ & $\mathrm{X}$ & $\mathrm{X}$ \\
\hline $23.00-23.59$ & $\mathrm{X}$ & $\sqrt{ }$ & $\mathrm{X}$ \\
\hline $00.00-00.59$ & $\mathrm{X}$ & $\mathrm{X}$ & $\sqrt{ }$ \\
\hline $01.00-01.59$ & $\sqrt{ }$ & $\mathrm{X}$ & $\mathrm{X}$ \\
\hline $02.00-02.59$ & $\mathrm{X}$ & $\sqrt{ }$ & $\mathrm{X}$ \\
\hline $03.00-03.59$ & $\mathrm{X}$ & $\mathrm{X}$ & $\sqrt{ }$ \\
\hline
\end{tabular}




\section{B. Pengujian sensor ultrasonik HC-SR04}

Pada pengujian sensor ultrasonik HC-SR04 dilakukan dengan membandingan jarak yang terukur oleh sensor ultrasonik HC-SR04 yang di tampilkan pada Serial Monitor dengan jarak pengukuran manual dengan meteran.

Pengukuran dilakukan pada dua titik pengukuran (TP) seperti terlihat pada gambar 51 berikut :

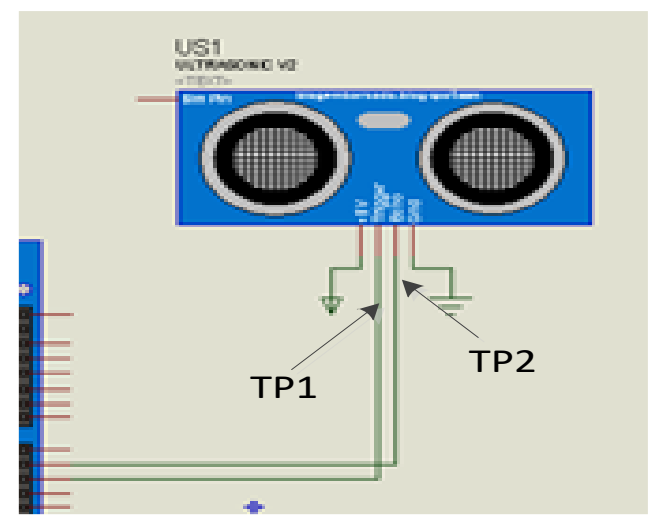

Gambar 11. Titik Pengukuran rangkaian sensor ultrasonik HCSR04

Tabel 11. Pengujian sensor ultrasonik HC-SR04 pada bak penampungan PDAM

\begin{tabular}{cccc}
\hline No & $\begin{array}{c}\text { jarak pembacaan } \\
\text { sensor }(\mathrm{cm})\end{array}$ & $\begin{array}{c}\text { jarak pembacaan } \\
\text { mistar }(\mathrm{cm})\end{array}$ & $\begin{array}{c}\text { persentase } \\
\text { kesalahan }(\%)\end{array}$ \\
\hline 1 & 13.18 & 13 & $1.37 \%$ \\
\hline 2 & 15.23 & 15 & $1.51 \%$ \\
\hline 3 & 17.34 & 17 & $1.96 \%$ \\
\hline 4 & 19.4 & 19 & $2.06 \%$ \\
\hline 5 & 21.18 & 21 & $0.85 \%$ \\
\hline 6 & 23.31 & 23 & $1.33 \%$ \\
\hline 7 & 25.48 & 25 & $0.81 \%$ \\
\hline 8 & 27.22 & 27 & $0.55 \%$ \\
\hline 9 & 29.16 & 29 & \\
\hline
\end{tabular}

Rata-rata persentase kesalahan $=1.37 \%$

Untuk menentukan nilai persentase kesalahan dapat di ukur dengan menggunakan rumus sebagai berikut:

persentase kesalahan $=\frac{\text { (jarak pembacaan sensor }- \text { jarak sebenarnya) }}{\text { jarak pembacaan sensor }} \times 100 \%$

Sensor ultrasonik merupakan sensor yang bekerja berdasarkan prinsip gelombang ultrasonik.Sensor ultrasonik bekerja dengan cara memicu pin trigger untuk memancarkan gelombang ultrasonik yang selanjutnya gelombang tersebut akan di pantulkan kembali oleh objek dan selanjutnya objek akan memantulkan kembali gelombang tersebut yang langsung di tangkap oleh pin Echo.

\section{Pengujian sensor waterflow}

Pengukuran sensor waterflow dilakukan pada tiga titik pengukuran (TP) seperti terlihat pada gambar 12 .

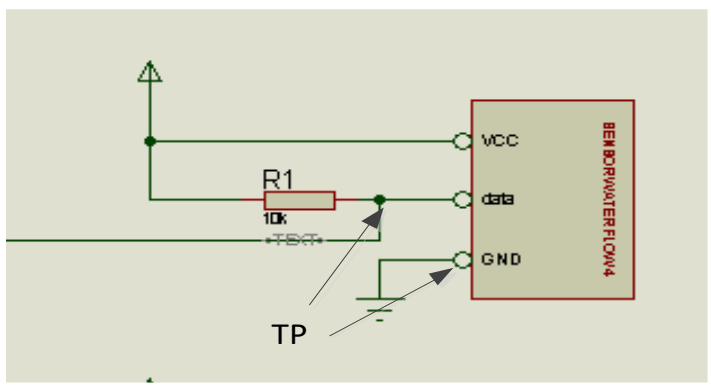

Gambar 12. Titik pengukuran pada sensor waterflow

Tabel 12. Hasil titik pengukuran pada rangkaian sensor water flow pada saat air mengalir

\begin{tabular}{ccc}
\hline \multirow{2}{*}{ Water flow } & \multicolumn{2}{c}{ Vout(V) } \\
\cline { 2 - 3 } & Saat dialiri air & Tidak di aliri air \\
\hline Pendistribusian awal & 2.64 & 0.02 \\
\hline Kran 1 & 2.58 & 0.02 \\
\hline Kran 2 & 2.55 & 0.02 \\
\hline Kran 3 & 2.52 & 0.02 \\
\hline
\end{tabular}

Sensor water flow terlebih dahulu di kalibrasi dengan menggunakan perbandingan volume yang terukur pada gelas ukur dengan volume pembacaan sensor water flow. Hasil kalibrasi dari sensor akan di ukur debit air bedasarkan volume yang terukur per menit dengan pembacaan debit pada sensor.

Tabel 13. Hasil pengujian kalibrasi volume sensor water flow pada sensor di pendistribusian awal

\begin{tabular}{cccc}
\hline \multirow{2}{*}{ No } & \multicolumn{2}{c}{ Volume $(\mathrm{mL})$} & $\begin{array}{c}\text { Persentase } \\
\text { kesalahan }(\%)\end{array}$ \\
\cline { 2 - 3 } & Gelas ukur & Pembacaan sensor & 1.2 \\
\hline 1 & 1000 & 988 & 0.41667 \\
\hline 2 & 1200 & 1195 & 0.5 \\
\hline 3 & 3000 & 2985 & 0.09091 \\
\hline 4 & 3300 & 3303 & 0.25 \\
\hline 5 & 4000 & 3990 & 0.06977 \\
\hline 6 & 4300 & 4303 & 0.32692 \\
\hline 7 & 5200 & 5217 & 0.15254 \\
\hline 8 & 5900 & 5909 & 0.29032 \\
\hline 9 & 6200 & 6218 & 0.375 \\
\hline 10 & 7200 & 7227 & 0.7375 \\
\hline 11 & 8000 & 7941 & 0.48889 \\
\hline 12 & 9000 & 9044 & 0.37 \\
\hline 13 & 10000 & 9963 & \\
\hline
\end{tabular}

Rata-rata persentase kesalahan $=0.4 \%$

Sensor water flow merupakan sensor yang bekerja menghasilkan pulsa frekuensi yang dihasilkan dari adanya perputaran medan magnet pada rotor sensor. Hasil pembacaan pulsa frekuensi digunakan untuk 
menentukan nilai debit air yang melewatinya berdasarkan tekanan air yang tersedia.

Tabel 14. Data pengukuran debit air pada saat penggunaan puncak dengan waktu $(04.00-08.59)$ dan $(15.00-18.59)$

\begin{tabular}{ccccc}
\hline \multirow{2}{*}{ No } & \multicolumn{4}{c}{ Debit pada pembacaan sensor (L/Min) } \\
\cline { 2 - 5 } & Pendistribusian awal & Kran 1 & Kran 2 & Kran 3 \\
\hline 1 & 6.3 & 1.9 & 1.8 & 1.9 \\
\hline 2 & 6.3 & 2 & 1.9 & 1.8 \\
\hline 3 & 6 & 2 & 1.8 & 1.8 \\
\hline 4 & 6.2 & 2 & 1.8 & 1.9 \\
\hline 5 & 6.2 & 2 & 1.8 & 1.9 \\
\hline 6 & 6 & 2 & 1.8 & 1.8 \\
\hline 7 & 6 & 1.9 & 1.9 & 1.9 \\
\hline 8 & 5.9 & 2 & 1.8 & 1.8 \\
\hline 9 & 6 & 2 & 1.8 & 1.8 \\
\hline 10 & 6 & 2 & 1.8 & 1.8 \\
\hline
\end{tabular}

Debit air yang mengalir pada pendistribusian awal tidak selalu sama dengan penjumlahan debit air pada masing-masing kran hal ini disebabkan oleh beberapa faktor yaitu adanya tekanan yang tidak sama pada setiap posisi sensor dan juga pada masing-masing kran air akan dibatasi dengan pembukaan valve berdasarkan sudut pembentuk servo serta jarak dari jangkauan air ke tujuan pendistribusian yang jauh. Berdasarkan rata-rata perbandingan debit air pada masing-masing kran didapatkan bahwa debit air yang mengalir hampir mendekati nilai yang konstan karena selisih dari pembacaan debit air di pendistribusian awal terhadap masing-masing kran konstan dan sangat kecil.

\section{Pengujian alat secara keseluruhan}

Proses pengujian alat pembacaan debit air pada masing-masing daerah yang dilakukan berdasarkan pada waktu. Proses pengambilan data dilakukan dengan pembacaan debit air pada masing-masing daerah berdasarkan pada waktu. Proses pembacaan data sensor akan dimonitoring pada thingspeak dan Delphi. Pengujian dilakukan dengan mengambil sampel data dengan waktu dari pukul 09.00 sampai 19.00 yang di ambil data per 15 menit yang mencakup terhadap seluruh penggunaan waktu.

Tabel 14. Hasil pengukuran secara keseluruhan

\begin{tabular}{ccccc}
\hline \multirow{2}{*}{ waktu } & \multicolumn{4}{c}{ Debit (L/Min) } \\
\cline { 2 - 5 } & Pendistribusian awal & Kran 1 & Kran 2 & $\begin{array}{c}\text { Kran } \\
3\end{array}$ \\
\hline 09.00 & 2.4 & 2.3 & 0 & 0 \\
\hline 09.15 & 2.4 & 2.3 & 0 & 0 \\
\hline 09.30 & 2.3 & 2.3 & 0 & 0 \\
\hline 09.45 & 2.4 & 2.4 & 0 & 0 \\
\hline 10.00 & 1.8 & 0 & 1.8 & 0 \\
\hline 10.15 & 1.9 & 0 & 1.8 & 0 \\
\hline 10.30 & 1.9 & 0 & 1.8 & 0 \\
\hline 10.45 & 1.9 & 0 & 1.8 & 0 \\
\hline 11.00 & 2.3 & 0 & 0 & 2.3 \\
\hline 11.15 & 2.3 & 0 & 0 & 2.3 \\
\hline 11.30 & 2.4 & 0 & 0 & 2.3 \\
\hline 11.45 & 2.4 & 0 & 0 & 2.3 \\
\hline 12.00 & 2.3 & 2.3 & 0 & 0 \\
\hline 12.15 & 2.3 & 2.3 & 0 & 0 \\
\hline 12.30 & 2.3 & 2.3 & 0 & 0 \\
\hline 12.45 & 2.3 & 2.3 & 0 & 0 \\
\hline
\end{tabular}

\begin{tabular}{ccccc}
\hline 13.00 & 1.9 & 0 & 1.9 & 0 \\
\hline 13.15 & 1.9 & 0 & 1.9 & 0 \\
\hline 13.30 & 1.9 & 0 & 1.9 & 0 \\
\hline 13.45 & 1.9 & 0 & 1.9 & 0 \\
\hline 14.00 & 2.3 & 0 & 0 & 2.3 \\
\hline 14.15 & 2.3 & 0 & 0 & 2.3 \\
\hline 14.30 & 2.3 & 0 & 0 & 2.3 \\
\hline 14.45 & 2.3 & 0 & 0 & 2.3 \\
\hline 15.00 & 6.2 & 1.9 & 1.8 & 2 \\
\hline 15.15 & 6.2 & 1.9 & 1.9 & 1.9 \\
\hline 15.30 & 6.5 & 1.9 & 1.9 & 2 \\
\hline 15.45 & 6.2 & 1.9 & 1.9 & 2 \\
\hline 16.00 & 6.2 & 1.8 & 1.9 & 2 \\
\hline 16.15 & 6.3 & 1.8 & 1.9 & 2 \\
\hline 16.30 & 6.3 & 1.8 & 1.9 & 2 \\
\hline 16.45 & 6.3 & 1.8 & 1.9 & 2 \\
\hline 17.00 & 6.2 & 1.8 & 1.9 & 2 \\
\hline 17.15 & 6.5 & 1.8 & 1.9 & 2 \\
\hline 17.30 & 6.5 & 1.8 & 1.9 & 2 \\
\hline 17.45 & 6.5 & 1.8 & 1.9 & 1.9 \\
\hline 18.00 & 6.5 & 1.8 & 1.9 & 1.9 \\
\hline 18.15 & 6.3 & 1.8 & 1.9 & 1.9 \\
\hline 18.30 & 6.3 & 1.8 & 1.9 & 1.9 \\
\hline 18.45 & 6.3 & 1.8 & 1.9 & 1.9 \\
\hline 19.00 & 2.3 & 2 & 0 & 0 \\
\hline
\end{tabular}

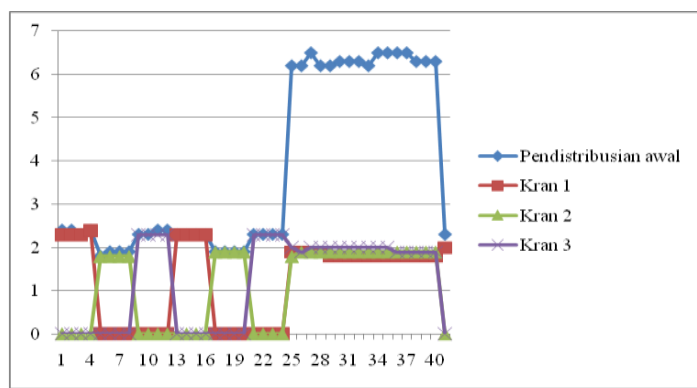

Gambar 20. Grafik perbandingan debit air

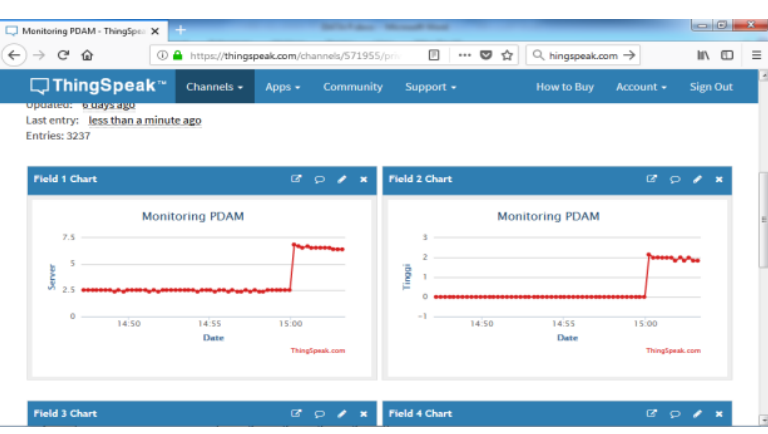

(a)

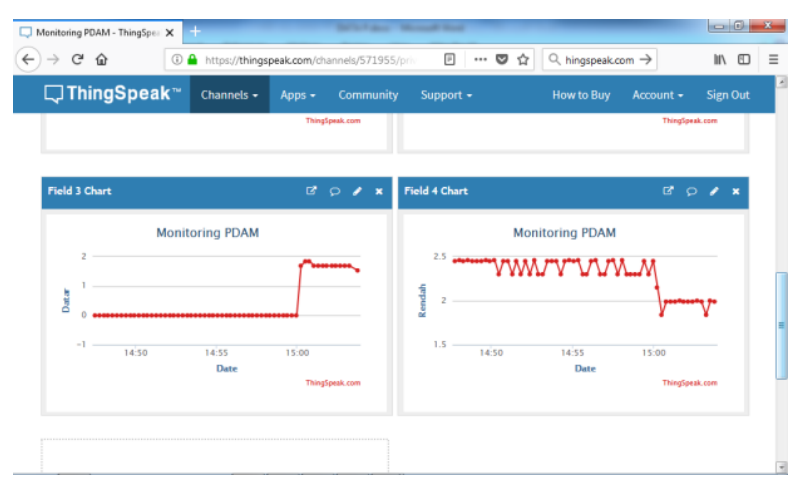

(b)

Gambar 21.(a) dan (b) tampilan pada thingspeak 


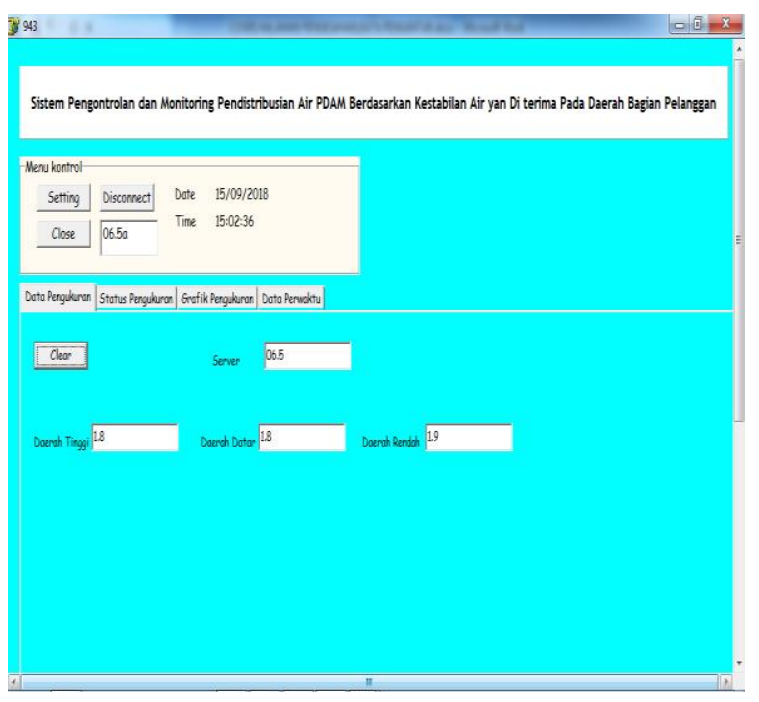

(a)

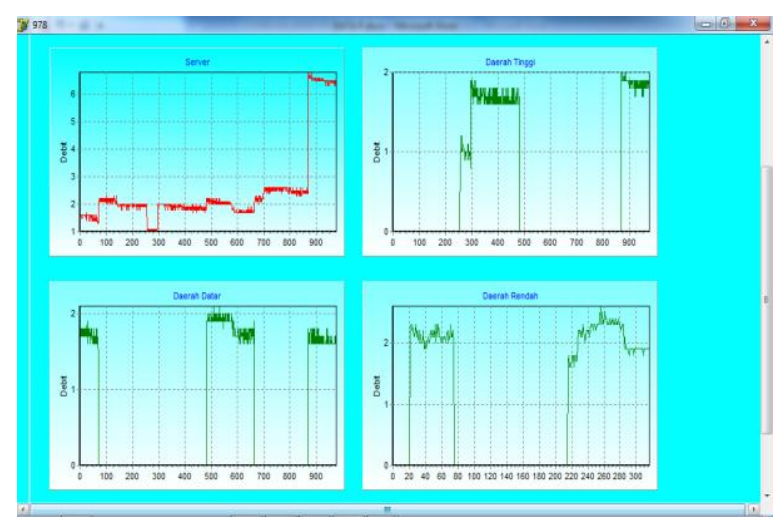

(b)

Gambar 22.(a) dan (b) tampilan pada Delphi

\section{KESIMPULAN}

Setelah melakukan perancangan, pembuatan, serta pengujian sistem dapat diambilk kesimpulan sebagai berikut. Perbandingan nilai waktu pada RTC lebih lambat sekitar 34 detik dibandingkan dengan waktu yang sebenarnya. Pembacaan nilai jarak dengan menggunakan sensor PING HC-SR04 memilki rentang pembacaan terhadap air di dalam bak penampungan dari jarak $15 \mathrm{~cm}-30 \mathrm{~cm}$ dengan menghasilkan rata-rata kesalahan pembacaan yaitu $1.37 \%$. Tingkat kesalahan dari pembacaan sensor water flow yang digunakan yaitu bervariasi antara $0.2 \%$ sampai $0.85 \%$. Pembacaan debit air yang dihasilkan pada saat waktu penggunaan puncak untuk kran 1 : 1.9 liter/menit, kran 2 : 1.8 liter/menit dan kran 3: 1.8 liter/menit. Debit air pada masing-masing kran pada waktu penggunaan biasa pada kran $1: 2.5$ liter/menit, kran $2: 2,5$ liter/menit dan kran $3: 2.5$ liter/menit sedangkan pada pendistribusian awal kran
$1: 2.3$ liter/menit kran $2: 2.5$ liter/menit dan pada kran $3: 2.3$ liter/menit.

Pengontrolan valve didasarkan dengan pembacaan waktu penggunaan yaitu jika waktu penggunaan puncak (04.00 sampai 08.59 dan 15.00 sampai 18.59) maka air akan mengalir pada ketiga daerah pendistribusian secara bersamaan. Jika waktu penggunaan biasa (09.00 sampai 14.59 dan 19.00 sampai 03.59) maka air akan didistribusikan secara bergantian

\section{REFERENSI}

[1] I. D. M. B. A. Darmawan, I. K. A. Mogi, and I. W. Santiyasa, "Sistem Instalasi Air Rumah Terkomputerisasi Berbasis Mikrokontroler Dengan Perintah Sms," JST (Jurnal Sains dan Teknol., vol. 6, no. 1, pp. 82-92, 2017, doi: 10.23887/jst-undiksha.v6i1.9388.

[2] I. P. L. Dharma, S. Tansa, and I. Z. Nasibu, "Perancangan Alat Pengendali Pintu Air Sawah Otomatis dengan SIM8001 Berbasis Mikrokontroler Arduino Uno," J. Tek., vol. 17, no. 1, pp. 40-56, 2019, doi: 10.37031/jt.v17i1.25.

[3] S. Program, S. Teknik, K. Fakultas, T. Dan, and I. Komputer, "Monitoring Distribusi Air Bersih," J. Ilm. SETRUM, vol. 5, no. $1,2016$.

[4] K. Diao, R. Sitzenfrei, and W. Rauch, "The impacts of spatially variable demand patterns on water distribution system design and operation," Water (Switzerland), vol. 11, no. 3, pp. 1-13, 2019, doi: 10.3390/w11030567.

[5] C. Passenberg, D. Meyer, J. Feldmaier, and H. Shen, "Optimal water heater control in smart home environments," 2016 IEEE Int. Energy Conf. ENERGYCON 2016, 2016, doi: 10.1109/ENERGYCON.2016.7513964.

[6] S. Chattoraj, "Smart Home Automation based on different sensors and Arduino as the master controller," Int. J. Sci. Res. Publ., vol. 5, no. 1, pp. 2250-3153, 2014, [Online]. Available: www.ijsrp.org.

[7] E. Madona, M. Irmansyah, and A. Nasution, "Sistem Informasi Untuk Posisi Dan Lama Duduk Dengan Smartphone Android Berbasis Mikrokontroler," vol. 10, pp. 2-6, 2018, [Online]. Available: http://jie.pnp.ac.id/index.php/jie/article/view/75/63.

[8] H. Singh, V. Pallagani, V. Khandelwal, and U. Venkanna, "IoT based smart home automation system using sensor node," Proc. 4th IEEE Int. Conf. Recent Adv. Inf. Technol. RAIT 2018, pp. 1-5, 2018, doi: 10.1109/RAIT.2018.8389037.

[9] B. N. Getu and H. A. Attia, "Automatic water level sensor and controller system," Int. Conf. Electron. Devices, Syst. Appl., 2017, doi: 10.1109/ICEDSA.2016.7818550. 